\title{
Insulin-like growth factor 1 and muscle growth: implication for satellite cell proliferation
}

\author{
Shuichi Machida ${ }^{1}$ and Frank W. Booth ${ }^{1,2 *}$ \\ ${ }^{1}$ Department of Biomedical Sciences and ${ }^{2}$ Department of Medical Pharmacology and Physiology and \\ the Dalton Cardiovascular Center, University of Missouri-Columbia, E102 Veterinary Medical Building, \\ 1600 East Rollins Road, Columbia, MO 65211, USA
}

\begin{abstract}
Insulin-like growth factor 1 (IGF-1) has been shown to rescue the aging-related or inactivityinduced loss of muscle mass through the activation of satellite cells. However, the signalling pathways and the mechanism by which IGF-1 affects satellite cells have not been not completely identified. The purpose of the present review is to provide current understanding of the cellular and molecular events underlying IGF-1 induced proliferation of satellite cells.
\end{abstract}

Insulin-like growth factor 1: Satellite cells

During the early stage of skeletal muscle development myoblasts fuse to form myotubes, which become innervated and develop into muscle fibres. Thereafter, skeletal muscle myonuclei are terminally post-mitotic and are unable to divide (O'Neill \& Stockdale, 1972). However, during postnatal growth and muscle hypertrophy, additional myonuclei are acquired via satellite cell fusion to the muscle fibre (Rosenblatt \& Parry, 1992). Satellite cells are small mononucleated cells that are located between the basal lamina and sarcolemma of muscle fibres. In adult skeletal muscles these cells are mitotically quiescent, but are activated and then proliferate in response to a number of stimuli, including mechanical loading, exercise and damage (Hawke \& Garry, 2001). Insulin-like growth factor 1 (IGF-1) is a potent mitogen, which is probably produced locally during muscle hypertrophy and can induce proliferation of satellite cells (Adams \& Haddad, 1996; Adams \& McCue, 1998). IGF-1 and satellite cells have been shown to play an essential role in the process of muscle hypertrophy (Rosenblatt \& Parry, 1992; Adams \& Haddad, 1996).

\section{Mechanical loading and insulin-like growth factor 1}

Mechanical loading, such as compensatory hypertrophy by muscle ablation (DeVol et al. 1990; Adams \& Haddad, 1996), stretch (Yang et al. 1997) and eccentric contraction (Yan et al. 1993) induce production of IGF-1 within the skeletal muscle. DeVol et al. (1990) have demonstrated a 3 -fold increase in total IGF-1 mRNA levels in the rat soleus and plantaris muscles after tenotomy-induced hypertrophy. Bamman et al. (2001) have extended the observation to human skeletal muscle, where $48 \mathrm{~h}$ after a single resistance training bout muscle IGF-1 mRNA increases. These reports suggest a relationship between local stimulation of skeletal muscle growth and IGF-1 expression. Skeletal muscle hypertrophy is regulated by at least three major molecular processes: (1) satellite cell activity; (2) gene transcription; (3) protein translation. IGF-1 can influence the activity of all these mechanisms, including increases in satellite cell proliferation, skeletal $\alpha$-actin mRNA expression and protein synthesis (Florini et al. 1996; Chakravarthy et al. 2000a). Thus, increased IGF-1 expression plays an important role in mediating muscle hypertrophy induced by mechanical loading (Adams \& Haddad, 1996; Adams \& McCue, 1998).

\section{Roles for insulin-like growth factor 1 and satellite cells in load-induced muscle hypertrophy}

Since myonuclei are post-mitotic, the hypertrophying skeletal muscle must rely on an alternative source for additional myonuclei (Rosenblatt \& Parry, 1992). Satellite cells have a tremendous proliferative capacity and are thought to be tissue-specific progenitor cells that are important in the hypertrophy and regeneration of skeletal 
muscle (Hawke \& Garry, 2001). The necessity for satellite cells for muscle hypertrophy was first demonstrated by Rosenblatt \& Parry (1992) in an experiment that prevented satellite cell proliferation by exposing the muscle to lowlevel $\gamma$-irradiation, with a resultant failure to produce full hypertrophy in response to functional overload. Thus, satellite cell proliferation is believed to be necessary for the full increase in skeletal muscle mass induced by overload. During the process of load-induced muscle hypertrophy, satellite cells are thought to proliferate, differentiate and then fuse with existing myofibres (Schultz \& McCormick, 1994). IGF-1 has been shown to stimulate these myogenic processes in skeletal muscles (Florini et al. 1996; Hawke \& Garry, 2001). For example, Adams \& Haddad (1996) have reported a positive correlation between muscle IGF-1 expression and the increase in muscle nuclear DNA content in the overloaded muscle. In addition, Adams \& McCue (1998) have found that localized infusion of IGF-1 into the skeletal muscles of rats in vivo results in hypertrophy and that DNA: protein of the hypertrophied muscles is unchanged from that of controls. These results indicate that the elevated muscle IGF-1 induced by loading may be contributing to the hypertrophy response, in part, by stimulating the proliferation of satellite cells. Recent data suggest that a specific IGF-1 isoform is expressed in muscle during overload hypertrophy (McKoy et al. 1999). This isoform, termed 'mechano growth factor' (i.e. IGF-1 Eb) by Geoffrey Goldspink, has been shown to be markedly up regulated in response to stretch and electrical stimulation, accompanied by an up-regulation of the liver form of IGF-1 (i.e. IGF-1 Ea) mRNA (McKoy et al. 1999). On the other hand, the same group (Owino et al. 2001; Hameed et al. 2003) has recently reported that mechanical overload and highresistance exercise induces the expression of mechano growth factor mRNA, while no changes are observed in the level of IGF-1 Ea mRNA.

\section{Effect of physical exercise on satellite cell proliferation}

An increased level of physical activity, such as running or resistance training, can also stimulate satellite cell mitotic activity (McCormick \& Thomas, 1992) and result in elevated satellite cell numbers (Kadi \& Thornell, 2000). Exercise training by progressive treadmill running results in the activation of satellite cells, in conjunction with morphological changes indicative of ongoing muscle fibre injury and repair (McCormick \& Thomas, 1992). Although local production of IGF-1 in skeletal muscle has been shown to increase after exercise (Hellsten et al. 1996), the cellular mechanism(s) linking exercise to increased IGF-1 is unclear.

\section{Insulin-like growth factor 1 can rescue sarcopenia}

Sarcopenia is the involuntary loss of skeletal muscle mass and strength that occurs with aging, resulting in physical frailty. One reason for sarcopenia may be that older skeletal muscles fail to respond to mechanical overload. For example, the gastrocnemius muscle of old rats fails to regrow after atrophy by limb immobilization (Chakravarthy et al. 2000b). Further, the mechanical loadinginduced up-regulation of mechano growth factor mRNA is attenuated in old muscles of human subjects and rats (Owino et al. 2001; Hameed et al. 2003). However, Barton-Davis et al. (1998) have demonstrated that IGF overexpression, using recombinant adeno-associated virus, rescues age-related muscle loss between the ages of 23 and 27 months in mice. Chakravarthy et al. (2000b) have extended the Barton-Davis et al. (1998) observation from normal-aged muscle to aged muscle forced to atrophy. They found that direct IGF-1 administration onto an atrophied muscle promotes an enhancement of satellite cell proliferation in culture and regrowth of skeletal muscle from limb immobilization in 30-month-old rats. These results suggest that satellite cells in skeletal muscle of 30-month-old rats are in sufficient quantity, but inactive as a result of lack of some endogenous growth factors, possibly including IGF-1. Thus, IGF-1 rescues muscle from sarcopenia, in part, through the proliferation of satellite cells.

\section{The mechanism by which insulin-like growth factor 1 stimulates satellite cell proliferation}

Unlike other growth factors, IGF-1 stimulates both myoblast proliferation and differentiation (Engert et al. 1996; Florini et al. 1996). In proliferating myoblasts IGF-1 increases the expression of the cell-cycle progression factors (Engert et al. 1996). After withdrawal of myoblasts from the cell cycle IGF-1 promotes muscle differentiation by inducing the expression or activity of myogenic regulatory factors (Musaro \& Rosenthal, 1999). The proliferative $v$. the differentiating functions of IGF-1 appear to be mediated by distinct intracellular signalling pathways (Coolican et al. 1997). Previous studies using immortalized myogenic cell lines such as L6A1 (Coolican et al. 1997), MM14 (Jones et al. 2001) and L8 (Tamir \& Bengal, 2000) have suggested that the mitogen-activated protein kinase mediates cellular proliferation, whereas the phosphatidylinositol 3-kinase (PI3K) pathway is activated during differentiation. However, although it is not clear what role the PI3K pathway plays in differentiation, recent evidence demonstrates a key role for the PI3K pathway in primary satellite cell proliferation (Chakravarthy et al. 2000a; Machida et al. 2003). Chakravarthy et al. (2000a) have demonstrated that IGF-I-stimulated proliferation of primary satellite cells isolated from transgenic mice overexpressing IGF-1 is associated with the activation of the PI3K/Akt signalling pathway, the up-regulation of a cyclin-dependent kinase 2 kinase activity and the downregulation of the cell-cycle inhibitor $\mathrm{p} 27^{\text {Kip } 1}$ (Chakravarthy et al. 2000a). Ectopic expression of p27 $7^{\text {Kipl }}$ has been shown to block the IGF-I-induced increase in satellite cell proliferation (Chakravarthy et al. 2000a). Thus, p27 Kip1 has been proposed to be a key regulatory factor, particularly in its ability to regulate satellite cell cycle progression. Machida et al. (2003) have recently reported that IGF-1 represses $\mathrm{p} 27^{\text {Kipl }}$ transcriptional activity through phosphorylation of Akt and forkhead transcription factor FOXO1, 
implying that FOXO1 may be an intermediary signal between Akt phosphorylation and p27 ${ }^{\text {Kip } 1}$ promoter activity in primary satellite cells of skeletal muscle.

\section{The other signal pathways contributing to insulin-like growth factor 1-induced satellite cell proliferation}

IGF-1 stimulates primary satellite cells to proliferate by increasing the phosphorylation of Akt/protein kinase B and FOXO1, down regulating $\mathrm{p} 27^{\text {Kip } 1}$, which in turn releases inhibition of cyclin-dependent kinase 2 , increasing phosphorylation of $\mathrm{pRb}$, allowing the cell cycle past the restriction point into the $\mathrm{S}$ phase (Chakravarthy et al. 2000a; Machida, 2003). IGF-1 also signals the janus kinase/signal transducers and activators of transcription pathway, but not the mitogen-activated protein kinase pathway in primary satellite cells ( $\mathrm{S}$ Machida and FW Booth, unpublished results).

\section{Summary}

There is now an increasingly aged population. IGF-1 has been shown to be able to rescue aging-related or inactivityinduced loss of muscle mass through the activation of satellite cells. The present review has compiled the current knowledge relating to the cellular and molecular events underlying IGF-1-induced proliferation of satellite cells. IGF-1 enhances satellite cell proliferation by decreasing the cell-cycle inhibitor p27 Kipl protein through the PI3K/Akt pathway (Fig. 1). Thus, p27 Kipl has been proposed to be a key regulatory factor, particularly in its ability to regulate satellite cell cycle progression.

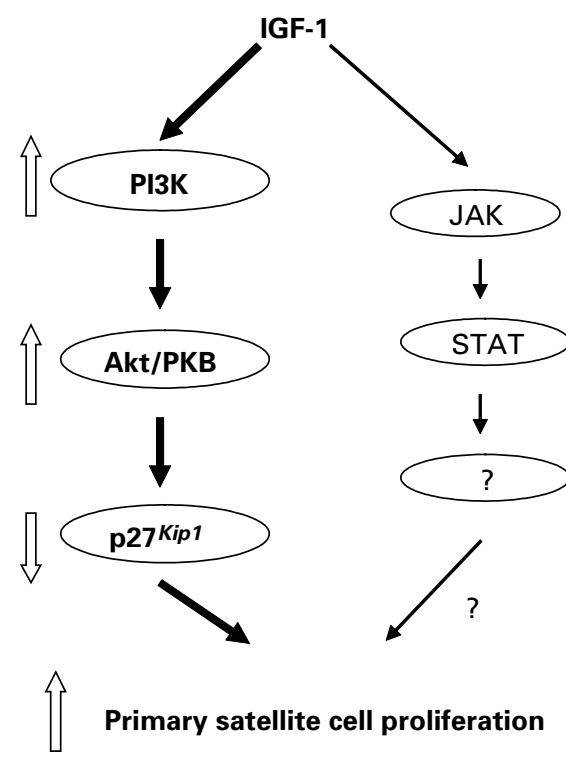

Fig. 1. Diagram of the signal transduction pathways by which insulin-like growth factor 1 (IGF-1) stimulates satellite cell proliferation. $\longleftarrow$, Changes in activity or status; $\longleftarrow, \longleftarrow$, flow of the IGF-1 signalling pathway. PI3K, phosphatidylinositol 3kinase; Akt/PKB, Akt/protein kinase B; JAK, janus kinase; STAT, signal transducers and activators of transcription.

\section{Acknowledgements}

Research was supported by NIH grant AG-18780 (FWB). Thanks to Dr Simon Lees for critical review.

\section{References}

Adams GR \& Haddad F (1996) The relationships among IGF-1, DNA content, and protein accumulation during skeletal muscle hypertrophy. Journal of Applied Physiology 81, 2509-2516.

Adams GR \& McCue SA (1998) Localized infusion of IGF-I results in skeletal muscle hypertrophy in rats. Journal of Applied Physiology 84, 1716-1722.

Bamman MM, Shipp JR, Jiang J, Gower BA, Hunter GR, Goodman A, McLafferty CL Jr \& Urban RJ (2001) Mechanical load increases muscle IGF-I and androgen receptor mRNA concentrations in humans. American Journal of Physiology 280, E383-E390.

Barton-Davis ER, Shoturma DI, Musaro A, Rosenthal N \& Sweeney HL (1998) Viral mediated expression of insulin-like growth factor I blocks the aging-related loss of skeletal muscle function. Proceedings of the National Academy of Sciences USA 95, 15603-15607.

Chakravarthy MV, Abraha TW, Schwartz RJ, Fiorotto ML \& Booth FW (2000a) Insulin-like growth factor-I extends in vitro replicative life span of skeletal muscle satellite cells by enhancing G1/S cell cycle progression via the activation of phosphatidylinositol 3'-kinase/Akt signaling pathway. Journal of Biological Chemistry 275, 35942-35952.

Chakravarthy MV, Davis BS \& Booth FW (2000b) IGF-I restores satellite cell proliferative potential in immobilized old skeletal muscle. Journal of Applied Physiology 89, 1365-1379.

Coolican SA, Samuel DS, Ewton DZ, McWade FJ \& Florini JR (1997) The mitogenic and myogenic actions of insulin-like growth factors utilize distinct signaling pathways. Journal of Biological Chemistry 272, 6653-6662.

DeVol DL, Rotwein P, Sadow JL, Novakofski J \& Bechtel PJ (1990) Activation of insulin-like growth factor gene expression during work-induced skeletal muscle growth. American Journal of Physiology 259, E89-E95.

Engert JC, Berglund EB \& Rosenthal N (1996) Proliferation precedes differentiation in IGF-I-stimulated myogenesis. Journal of Cell Biology 135, 431-440.

Florini JR, Ewton DZ \& Coolican SA (1996) Growth hormone and the insulin-like growth factor system in myogenesis. Endocrine Reviews 17, 481-517.

Hameed M, Orrell RW, Cobbold M, Goldspink G \& Harridge SD (2003) Expression of IGF-I splice variants in young and old human skeletal muscle after high resistance exercise. Journal of Physiology (London) 547, 247-254.

Hawke TJ \& Garry DJ (2001) Myogenic satellite cells: physiology to molecular biology. Journal of Applied Physiology 91, 534-551.

Hellsten Y, Hansson HA, Johnson L, Frandsen U \& Sjodin B (1996) Increased expression of xanthine oxidase and insulinlike growth factor I (IGF-I) immunoreactivity in skeletal muscle after strenuous exercise in humans. Acta Physiologica Scandinavica 157, 191-197.

Jones NC, Fedorov YV, Rosenthal RS \& Olwin BB (2001) ERK1/2 is required for myoblast proliferation but is dispensable for muscle gene expression and cell fusion. Journal of Cellular Physiology 186, 104-115.

Kadi F \& Thornell LE (2000) Concomitant increases in myonuclear and satellite cell content in female trapezius muscle following strength training. Histochemistry and Cell Biology 113, 99-103. 
McCormick KM \& Thomas DP (1992) Exercise-induced satellite cell activation in senescent soleus muscle. Journal of Applied Physiology 72, 888-893.

McKoy G, Ashley W, Mander J, Yang SY, Williams N, Russell B \& Goldspink G (1999) Expression of insulin growth factor-1 splice variants and structural genes in rabbit skeletal muscle induced by stretch and stimulation. Journal of Physiology (London) 516, 583-592.

Machida S, Spangenburg EE \& Booth FW (2003) Forkhead transcription factor FoxO1 transduces insulin-like growth factor's signal to $\mathrm{p} 27^{\text {Kipl }}$ in primary skeletal muscle satellite cells. Journal of Cellular Physiology 196, 523-531.

Musaro A \& Rosenthal N (1999) Maturation of the myogenic program is induced by postmitotic expression of insulin-like growth factor I. Molecular and Cellular Biology 19, 3115-3124.

O’Neill MC \& Stockdale FE (1972) Differentiation without cell division in cultured skeletal muscle. Developmental Biology 29, 410-418.

Owino V, Yang SY \& Goldspink G (2001) Age-related loss of skeletal muscle function and the inability to express the autocrine form of insulin-like growth factor-1 (MGF) in response to mechanical overload. FEBS Letters $\mathbf{5 0 5}$, 259-263.

Rosenblatt JD \& Parry DJ (1992) Gamma irradiation prevents compensatory hypertrophy of overloaded mouse extensor digitorum longus muscle. Journal of Applied Physiology 73, 2538-2543.

Schultz E \& McCormick KM (1994) Skeletal muscle satellite cells. Reviews of Physiology Biochemistry and Pharmacology 123, 213-257.

Tamir Y \& Bengal E (2000) Phosphoinositide 3-kinase induces the transcriptional activity of MEF2 proteins during muscle differentiation. Journal of Biological Chemistry 275, 34424-34432.

Yan Z, Biggs RB \& Booth FW (1993) Insulin-like growth factor immunoreactivity increases in muscle after acute eccentric contractions. Journal of Applied Physiology 74, 410-414.

Yang H, Alnaqeeb M, Simpson H \& Goldspink G (1997) Changes in muscle fibre type, muscle mass and IGF-I gene expression in rabbit skeletal muscle subjected to stretch. Journal of Anatomy 190, 613-622. 